\title{
Opportunities for Social Knowledge Creation in the Digital Humanities
}

Alyssa Arbuckle

Over the past decade or so, digital humanities discussions and initiatives have become more socially oriented. ${ }^{i}$ Many digital humanities practitioners are reconsidering their role in the public sphere, both in regard to the often biased structures they work in, as well as how they can better collaborate and share with wider communities. This is not to say that the digital humanities have accomplished some advanced degree of public engagement, diversity, or inclusion. They haven't. Rather, a disciplinary turn toward matters of social justice, collaboration, and social media acknowledges a changing tide of consciousness around how an academic field is constituted, as well as what its role is (or could be) in the larger social sphere.

A reconsideration of the importance of social contexts, roles, and practices is afoot for personal, professional, political, and even economic reasons. As early as 1995, David W. Brown attributed government funding cuts to academics' unwillingness to engage with the public. More recent research has echoed Brown's sentiments (Jay n.p.). In the humanities, an affirmative response to this perennial call for engagement has formalized under the banner of the "public humanities," and as Sheila A. Brennan writes, "Public history and humanities practices - in either digital or analog forms - place communities, or other public audiences, at their core" (384). Opportunities emerge for digital humanities practitioners to create knowledge with each other and with members of the broader public as the humanities continue this trajectory toward social practices, considerations, and analyses. Anne Burdick et al. write in "The Social Life of the Digital Humanities,"

New modes of knowledge formation in the digital humanities are dynamically linked to communities vastly larger and more diverse than those to which the academy has been accustomed. These communities increasingly demand and delight in sociable intellectual interactions... (75)

I interpret this claim of dynamic linkages, diverse communities, and public demand for interaction as a call to action. In response to such a call, I argue in this chapter that the digital humanities, as a field, is well poised to embrace social knowledge creation practices, and I aim to synthesize current thinking around social knowledge creation. I begin with a brief description of the premise of social knowledge creation. From there, I touch on the necessary factors that are in place to encourage social knowledge creation in the digital humanities: collaboration across groups, alternative academic publishing practices, available technology and skills, engagement with social media, open access to research, and public humanities lessons. In closing, I reinforce that the current state of digital humanities, and that of the academy more broadly, is ideal for social knowledge creation practices to proliferate. In taking advantage of this timely opportunity, academia might serve the public that funds it more readily, as well as move toward the goal of creating and sharing knowledge more widely and more democratically.

\section{Social Knowledge Creation: What Is It?}


Elsewhere, my colleagues and I have described social knowledge creation as "acts of collaboration in order to engage in or produce shared cultural data and/or knowledge products" (Arbuckle et al. 30). As a concept, social knowledge creation acknowledges the inherent sociality of knowledge work, and that no knowledge is created in a vacuum. But social knowledge creation, as a term, also encourages academics to look beyond the de facto collaboration of their daily practices (e.g., teaching students, consulting colleagues, researching, networking, publishing, and attending conferences) in order to consider how their work could be more socially oriented, even if, or perhaps especially because, the daily collaborations of academic work "seem so obviously part of our academic life that we have ceased to notice them," as Geoffrey Rockwell claims (136).

Knowledge creation is innately iterative and collaborative, and has been since its inception: it relies on building arguments and fostering ideas out of the previous work of other scholars. As Isaac Newton famously quipped, "If I have seen further it is by standing on the shoulders of giants." In the twenty first century, knowledge creation is uniquely positioned in a social, networked environment predicated on rapid communication and collective interaction. Such an environment has brought academics and diverse members of the general public to the same table (or social networking site) at an unprecedented scale. In doing so, multiple communities are now able to communicate and develop knowledge products together, as evinced in initiatives like the massive online community-produced Wikipedia. This state of interaction is a significant departure from previous assumptions about the university's purported monopoly on knowledge creation. For many, this is a welcome change. As Damien Smith Pfister suggests, many-to-many communication disrupts traditional knowledge practices that depend on specialized experts to disseminate knowledge through carefully regulated channels and institutions. The networked social environment, by contrast, can be a more participatory and representative space-a space better suited for social knowledge creation.

\section{Social Knowledge Creation and the Digital Humanities}

The constitution of the digital humanities is well suited to social knowledge creation. Digital humanities practitioners are lauded for their in-house and interdisciplinary collaborations. Due to early adoption of social media, Twitter has become a surrogate coffeehouse for geographically dispersed digital humanists, and the latest theoretical, disciplinary, and community discussions happen publicly and in real time (Warwick 210-11). Hands-on experimentation with publishing has also flourished in the digital humanities (e.g. Manifold Scholarship, Scalar), perhaps especially because many practitioners have the technical understanding and skill to create or customize online publications and platforms. Finally, the Open Access movement has been widely supported in the digital humanities, even though it has yet to gain traction in some of the more traditional humanities fields, and even though we need to think beyond straightforward access to research. In his touchstone book on open access The Access Principle: The Case for Open Access to Research and Scholarship (2006), John Willinsky opines, "were the spirit willing, the technology is ready" (118) — that is, a global open access system that provides free access to all published research is feasible from a technical standpoint; it is the cultural mores, governing policies, commercial interests, and scholarly activities that require transformation. I suggest that the same may be true of 
social knowledge creation in the digital humanities: if the spirit is willing, the technology is ready. In what follows I detail the interconnected roles of collaboration, social media, publishing, technology, and open access within the larger digital humanities landscape, and explore how these elements contribute to an environment for sustained social knowledge creation.

The development and sustenance of the networked, social, online environments in which many digital humanities practitioners live and work has emphasized how inherent collaboration is to the field. My purposeful assertion of collaboration as an "inherent quality" of the digital humanities may seem strange to those who work in the sciences, where lab research, group fieldwork, citizen contributions, and co-authorship are accepted as trademarks of the profession. But the collaborative nature of scholarship in the humanities has often been overlooked. If the sciences are identified with a widely accepted vision of well-staffed labs, the humanities are more often fixed in the communal consciousness as frazzled lone scholars in dusty studies. In the oft-cited Planned Obsolescence: Publishing, Technology, and the Future of the Academy (2011), Kathleen Fitzpatrick further links the disregard of collaboration in the humanities to the profession's idealization of single authorship: "what we will need to let go of," she writes, "is not what we have come to understand as the individual voice, but rather the illusion that such a voice is ever fully alone" (11). From a historical standpoint, the Romanticist notion of the Author (and the Author as Genius) may still linger with those who study Percy Shelley, William Wordsworth, and Samuel Taylor Coleridge, as well as the poets, authors, and artists who came before and after them. This Romantic hangover has contributed, in part, to the rise of the celebrity academic and an insistence on the importance of single-authored publications. In the introduction to Editors and the Social Text Darcy Cullen writes, "The publishing process is a collaborative one, involving the combined efforts of authors, editors, typesetters, proofreaders, indexers, printers, and marketers, each of which introduces a network of relationships" (3). She argues that the role of the editor in academic publishing has often been overshadowed, largely due to the Author/Genius fable and the academy's proclivity to advance and award the individual scholar. Cullen refers to this phenomenon as the "myth of the invisible editor" (7), an internalized conception that editors (and, in fact, all those involved in knowledge production) should be silent, invisible accomplices to the development of an Author's work, and that they should not be recognized too prominently for their contributions, as this might devalue the Author's aura. Not only is the propagation of the unrealistic Author/Genius misleading, it is also contra to the belief that knowledge creation is a democratic, multiplayer endeavor and should be represented - with due credit—as such.

In the chapter "Towards Best Practices in Online Collaborative Knowledge Production," Canada Research Chair in Collaborative Digital Scholarship Susan Brown provides an overview of effective, digital, collaborative research in the humanities. She calls collaboration in the digital humanities "pervasive," and notes that the most pertinent reasons for this pervasiveness include the ability to draw on varied skills sets and different disciplinary frameworks, to involve people with different levels of expertise including for pedagogical and mentoring purposes, to scale up research by involving a larger number of people than is usual in humanities research (potentially including citizen scholars from beyond academia), and to allow contributors to work asynchronously and across distances. (49) 
In fact, it is difficult to imagine a digital humanities or digital scholarship project that does not rely, to some degree, on working with other people. As Brown notes, digital projects require varied skillsets from different disciplines; beyond this, digital projects are generally far too time- and laborintensive to be tackled by one person (Rockwell 135). Even those who claim to work individually on a digital humanities project still rely on databases, programming languages, or code libraries that have been developed by others. Alex Gil and Élika Ortega reinforce this notion when they write that digital humanities is " $[\mathrm{k}]$ nown and largely valued by its collaborative culture and commitment to openness" (22). It is notable that Brown also references "including citizen scholars from beyond academia" as a collaboration factor in digital humanities work. For Brown, digital humanities projects can engage with larger publics more readily than traditional humanities work, if only because of scale and scope. This phenomenon is most often seen in large, online crowdsourcing projects. George Veletsianos defines crowdsourcing as "the process of gathering contributions from large groups of individuals in order to solve a common problem or tackle a challenge" (40); Rockwell describes it as a practice that "uses social media tools like wikis to enable a 'crowd' or group of people to create something of value" (139). Among other projects, this practice is evident in the popular Transcribe Bentham, the well-known digital humanities crowdsourcing initiative based out of University College London that relies on amateur volunteers to transcribe digitized versions of philosopher Jeremy Bentham's writings (Causer and Terras).

When academics acknowledge intellectual output as socially created, the rightful recognition and promotion of others' contributions becomes more common. Such a collaborative mindset brings us closer to Fitzpatrick's exhortation that academics must let go of the myth of the solitary scholarly voice. Rather, multiplayer knowledge creation is much more representative of the technologyfacilitated communication and engagement that has become a distinct pattern of twenty first century social fabric. On social media platforms in particular, various content creators engage in the same or adjacent online spaces, where their contributions can be tracked, recorded, and credited. Whether users choose to act as realistic avatars, fantasy alter egos, or anonymous enigmas, their online activity is traceable and archivable, providing a much more realistic sense of the many hands that shape knowledge output. Although a conception of the university as a Members Only ivory tower for the elite persists, social technologies have become both common denominator and accessible amplifier for people of varied backgrounds, geographical locations, educational experiences, and social statuses. The technology is in place, and a more overt acknowledgement of collaboration has developed. How can digital humanities practitioners now extend their collaborative behavior into working with broader publics via the technological means at their disposal?

Social media platforms can become potent sites of social knowledge creation due to their large, diverse participant base. Although access is technology- (and thus resource-) dependent, millions of people from all over the world interact online via social media. The existence of a colocated critical mass presents an unprecedented opportunity for wide scale connection and communication. James O’Sullivan, Christopher P. Long, and Mark A. Mattson argue that social media has also enabled greater professional and public interaction in academia, and in doing so contributes to the current shift toward sociality and openness. Further, they suggest, 
[w] hen we speak of openness, it is not just a case of liberating publications of economic barriers, it is about sharing, in the broadest sense: social media present scholars with an opportunity to share knowledge, in all of its various forms, be that a 140-character epiphany or a 6,000-word peer-reviewed research article on an esoteric subject matter. (385)

O’Sullivan, Long, and Mattson celebrate social media platforms for the connection and knowledge dissemination opportunities they bear. Certain projects demonstrate the possibilities of social mediafueled interaction for scholarly work. For example, A Social Edition of the Devonshire Manuscript is a Wikibooks edition of a sixteenth century verse miscellany that employs social media practices in order to open the Devonshire Manuscript to varied publics (Crompton et al.). The edition is open for anyone to read, add to, or edit, and members of the Devonshire Manuscript Editorial Team monitor the edition as well as engage with the public via the Wikimedia platform and Twitter. In Social Media in Academia: Networked Scholars (2016), Veletsianos also explores the affirmative opportunities that social media bears. He considers social media participation as the mark of the networked scholar, and lauds social media for its interdisciplinary appeal, role in shifting perspectives about academia, and capacity for connecting scholars with each other and with broader publics in ways not possible prior to Web 2.0 technologies. Veletsianos is also critical of social media, however, especially for the hate speech, racism, misogyny, and general harassment that runs rampant on popular social media sites like Facebook, Twitter, and Reddit. He considers social media as a possible replicator of inequality in the academy, where those who have access to personal computers, are technologically savvy, and possess a high level of digital literacy gain more popularity and visibility than those who do not have such skills or privileges. Veletsianos calls for paradigmatic shifts in the thinking around higher education practices in order to enhance and train for emerging forms of networked scholarship_-including social media practices.

As stated above, alternative approaches to academic publishing can also facilitate social knowledge creation. For centuries, academics relied on printers and publishers to disseminate their research. But in the twenty first century, networked technology has become increasingly accessible, and many working in the academy have developed technical content production and dissemination skills. On a parallel current, journal subscription costs have risen to an unprecedented level, effectively cutting off access to academic research for many libraries that simply cannot afford it. Many believe that the current situation is both untenable and unacceptable, as corporate publishers of academic material continue to make massive profits from publishing publicly funded research and selling it back to libraries that are already dealing with lowered budgets. This high-pressure environment has led to a rethinking of what the purpose of academic publishing is, as well as who should be at the helm of scholarly communication - perhaps most aptly synthesized by Fitzpatrick in Planned Obsolescence. She writes, "Changing our technologies, our ways of doing research, and our modes of production and distribution of the results of that research are all crucial to the continued vitality of the academy" (10). Fitzpatrick notes that universities in general, but the humanities in particular, must adapt to new networked technologies in order to resist becoming irrelevant to larger society (13-14). When the barriers to entry for developing and using diverse digital dissemination platforms lower, and production skills improve, an opportunity arises for researchers and authors to re-acquaint with the means and modes of their scholarly production. As Willinsky writes, "Online 
publishing technologies are drawing women and men of knowledge back to the (digital) typeface" (191). Elsewhere, my colleague Alex Christie and I suggest that authors can now "develop and disseminate their research and ideas through various avenues, and in many forms and formats, afforded by digital means" (n.p.) Further, we state, "scholars can apply critical insight and creative practice to the development of technologies and platforms through which research is shared and disseminated, allowing an unprecedented level of scholarly intervention in intellectual and cultural exchange" (Arbuckle and Christie n.p). The establishment of digital humanities as a field, the many undergraduate and graduate student, faculty, or librarian-run online journals, and the development of more creative publishing tools and platforms all bode well for a future academic publishing system with interests shifted from prestige and profit for the few to access and relevance for the many.

Digital humanities practitioners are well positioned to explore alternative academic publishing options, including those predicated on social interaction and / or widespread dissemination. Uniquely, digital humanities involves both computational and humanistic proclivity, understanding, and skill. In his book The Emergence of the Digital Humanities (2013), Steven E. Jones reiterates that academic practitioners can take the means of producing scholarly work into their own hands now more than ever, as they have the know-how to develop or modify scholarly production systems. Rather than relying on scholarly communication systems already in place, practitioners can experiment with different modes, media, and models of publication. They have expertise in humanities subjects as well as professional associations and collaborative relationships with other humanities, computer science, and library colleagues. And, as suggested earlier, there is a rising tide of social-mindedness in the field. John Maxwell claims that most scholarly communication platforms to date have simply been a means to expedite and render more efficient traditional writing and publishing practices. This is not entirely negative, from my perspective: it is necessary to explore how technology can make scholarly communication more efficient. Maxwell argues, however, that the potential for creative, agile, and social publication modes is substantial and yet untapped by hitherto conservative attitudes and methods. A social knowledge creation approach to alternative scholarly communication modes could harness the opportunities of networked technology to create research output that is engaging to many different audiences, not only to the small number of scholarly readers who engage their colleagues' articles.

A key element of the shift toward alternative academic publishing practices is the Open Access movement. Described succinctly by Peter Suber as "digital, online, free of charge, and free of most copyright and licensing restrictions" (4), open access is predicated on the notion that access to research is a public good, and that publicly-funded research should be publicly-available. Of course, these conceptions run counter to much of the current scholarly publishing system, especially as it has developed since the Second World War and the resultant influx of journal publishing. The rush to digitize journals in the 1990s also led many scholarly societies to enter into agreements with those who had the economic and technological wherewithal to undertake digital journal production - that is, commercial publishers. At present, these commercial publishers - who do not financially remunerate authors or peer reviewers for their labor-publish the majority of vetted academic research and sell this product back to university libraries at exorbitant costs via subscription-based journals and inflexible journal packages. Open access advocates are pushing for 
a more just system where peer-reviewed research is openly shared across institutional and national boundaries (Suber; Willinsky). Without such access to intellectual and cultural resources, social knowledge creation in digital humanities is limited. Academic publishing practices must become more open if scholars are to collaborate and produce knowledge with those outside of their own departments, never mind those without an official role in the higher education apparatus at large.

Beyond the pragmatic and conceptual necessities of straightforward access to academic work, there is also the question of knowledge uptake and mobilization. It is misguided to believe that uploading one's research article to academia.edu automatically constitutes a dramatically increased level of public engagement (McGregor and Guthrie). As digital content creators in advertising will relate, simply posting an article or project on the Internet for free does not immediately garner a sustained audience or engaged community. In "Lessons on Public Humanities from the Civic Sphere," Wendy Hsu discusses her public humanities work with the City of Los Angeles Department of Cultural Affairs. She emphasizes the value of digital humanities practitioners interacting with different community groups to collaboratively share and create knowledge. But Hsu also pushes back against the conception that scholarship is a gift to society or a de facto public good; rather, she argues, "Using the digital to learn from the public is a listening practice, one that yields more efficacious and engaged public humanities work" (281). It is not enough to simply provide access to research as a benevolent present to imagined others; rather, if digital humanities practitioners are intent on social knowledge creation, they must acknowledge the sociality of knowledge production and connect with community groups in early stages of research and development to build truly collaborative relationships. As Brennan writes, "It is important to recognize that projects and research may be available online, but that status does not inherently make the work digital public humanities or public digital humanities" (384). The digital humanities is not intrinsically public despite its integration with technology and prevalence in online spaces. Nonetheless, the unique position of digital humanities practitioners within these networked, social spaces is an opportunity to rethink scholarly practices and explore possibilities for increased social knowledge creation.

\section{Conclusion}

The stage is set for the growth of social knowledge creation practices in the digital humanities, but further action is still required for digital humanities research to become more valuable, engaging, and relevant in the public sphere. Scholars, institutions, governments, and the public need to become more attuned to the necessity of open access for more academic and cultural material to become available for shared knowledge production. Digital humanities practitioners need to learn from their public humanities colleagues when undertaking publicly integrated initiatives. Humanities scholars must acknowledge the value and prevalence of collaboration, and seek out ways to foster it. Researchers need to build on their increasing familiarity with the affordances of social media and other online technologies and use such platforms for shared knowledge creation and public engagement. When scholars explore alternative scholarly communication modes and methods that deviate from the closed circuit, small audience model of traditional scholarly publishing, the prospect of more innovative, open knowledge dissemination can arise. Among all these possibilities 
for social knowledge creation and the digital humanities, an important lesson remains: the focus on social cannot be an afterthought, once the paper is published and the $\mathrm{CV}$ is updated. Nor can we uncritically embrace each new revolution in technology without thinking carefully about its structure, purpose, and affordances. In order to connect across perceived social and institutional boundaries, academics must consider opportunities for broad collaboration at the inception of their research initiatives and inquiries, with a full understanding of the possibilities and perils involved. In this way, we might encourage opportunities for social knowledge creation in the digital humanities to bloom. 


\section{Works Cited}

The Alliance for Networking Visual Culture. Scalar. <https://scalar.me/anvc/scalar/>

Arbuckle, Alyssa, Nina Belojevic, Tracey El Hajj, Randa El Khatib, Lindsey Seatter, and Raymond G. Siemens, with Alex Christie, Matthew Hiebert, Jon Saklofske, Jentery Sayers, Derek Siemens, Shaun Wong, and the INKE and ETCL Research Groups. "An Annotated Bibliography of Social Knowledge Creation." Social Knowledge Creation in the Humanities: Volume 1. Ed. Alyssa Arbuckle, Aaron Mauro, and Daniel Powell. Arizona: Iter Academic Press and Arizona Center for Medieval and Renaissance Studies, 2017. 29-264.

Arbuckle, Alyssa, and Alex Christie, with the ETCL, INKE, and MVP Research Groups. "Intersections Between Social Knowledge Creation and Critical Making." Scholarly and Research Communication 6.3 (2015): n.p. http://srconline.ca/index.php/src/article/viewFile/200/426

Brennan, Sheila A. "Public, First." Debates in the Digital Humanities 2016. Ed. Matthew K. Gold and Lauren A. Klein. Minneapolis: University of Minnesota Press, 2016. 384-89.

Brown, David W. “The Public/Academic Disconnect.” Higher Education Exchange (1995): 38-42.

Brown, Susan. "Towards Best Practices in Online Collaborative Knowledge Production.” Doing Digital Humanities. Ed. Constance Crompton, Richard Lane, and Raymond G. Siemens. London and New York: Routledge, 2016. 47-64.

Burdick, Anne, Johanna Drucker, Peter Lunenfeld, Todd Presner, and Jeffrey Schnapp. "The Social Life of the Digital Humanities.” Digital_Humanities. Cambridge, MA: MIT Press, 2012. 73-98.

Causer, Tim, and Melissa Terras. "Crowdsourcing Bentham: Beyond the Traditional Boundaries of Academic History.” International Journal of Humanities and Arts Computing 8.1 (2014): 46-64. http://dx.doi.org/10.3366/ijhac.2014.0119

Crompton, Constance, Daniel Powell, Alyssa Arbuckle, and Ray Siemens, with Maggie Shirley and the Devonshire Manuscript Editorial Group. "Building A Social Edition of the Devonshire Manuscript." Renaissance and Reformation / Renaissance et Réforme 37.4 (2014): 131-56.

Cullen, Darcy. "Introduction: The Social Dynamics of Scholarly Editing." Editors, Scholars, and the Social Text. Toronto: University of Toronto Press, 2014. 3-32.

Fitzpatrick, Kathleen. Planned Obsolescence: Publishing, Technology, and the Future of the Academy. New York: New York University Press, 2011. 
Gil, Alex, and Élika Ortega. "Global Outlooks in Digital Humanities.” Doing Digital Humanities. Ed. Constance Crompton, Richard Lane, and Raymond G. Siemens. London and New York: Routledge, 2016. 22-34.

Hockey, Susan. "Digital Humanities in the Age of the Internet: Reaching Out to Other Communities." Collaborative Research in the Digital Humanities. Ed. Marilyn Deegan and Willard McCarty. Surrey, England: Ashgate, 2012. 81-92.

Hsu, Wendy. "Lessons on Public Humanities from the Civic Sphere." Debates in the Digital Humanities 2016. Ed. Matthew K. Gold and Lauren A. Klein. Minneapolis: University of Minnesota Press, 2016. 280-86.

Jay, Gregory. "The Engaged Humanities: Principles and Practices for Public Scholarship and Teaching." Journal of Community Engagement and Scholarship 3.1 (2012): 51-63.

Jones, Steven E. "Publications." The Emergence of the Digital Humanities. London and New York: Routledge, 2013. 147-77.

Losh, Elizabeth. "Hacktivism and the Humanities: Programming Protest in the Era of the Digital University." Debates in the Digital Humanities. Ed. Matthew K. Gold. Minneapolis: University of Minnesota Press, 2012. 161-86.

Liu, Alan. "Where is Cultural Criticism in the Digital Humanities?" Debates in the Digital Humanities. Ed. Matthew K. Gold. Minneapolis: University of Minnesota Press, 2012. 490-510.

Maxwell, John W. "Beyond Open Access to Open Publication and Open Scholarship." Scholarly and Research Communication 6.3 (2015): n.p. http://srconline.ca/index.php/src/article/view/202.

McGregor, Heidi, and Kevin Guthrie. "Delivering Impact of Scholarly Information: Is Access Enough?” Journal of Electronic Publishing 18.3 (2015): n.p. http://quod.lib.umich.edu/j/jep/3336451.0018.302?view=text;rgn=main.

McPherson, Tara. "Why are the Digital Humanities So White? or Thinking the Histories of Race and Computation." Debates in the Digital Humanities. Ed. Matthew K. Gold. Minnesota: University of Minnesota Press, 2012. 139-60.

O’Sullivan, James, Christopher P. Long, and Mark A. Mattson. "Dissemination as Cultivation: Scholarly Communications in a Digital Age." Doing Digital Humanities. Ed. Constance 
Crompton, Richard Lane, and Raymond G. Siemens. London and New York: Routledge, 2016. 384-97.

Pfister, Damien Smith. "Networked Expertise in the Era of Many-to-Many Communication: On Wikipedia and Invention." Social Epistemology: A Journal of Knowledge, Culture and Policy 25.3 (2011): 217-31. doi:10.1080/02691728.2011.578306.

Rockwell, Geoffrey. "Crowdsourcing the Humanities: Social Research and Collaboration." Collaborative Research in the Digital Humanities. Ed. Marilyn Deegan and Willard McCarty. Surrey, England: Ashgate, 2012. 135-54.

Suber, Peter. Open Access. Cambridge, MA: MIT Press, 2012.

Svensson, Patrik. "Beyond the Big Tent." Debates in the Digital Humanities. Ed. Matthew K. Gold. Minneapolis: University of Minnesota Press, 2012. 36-49.

University of Minnesota Press. Manifold Scholarship. https://manifold.umn.edu/

Veletsianos, George. Social Media in Academia: Networked Scholars. New York and London: Routledge, 2016.

Warwick, Claire. "Institutional Models for Digital Humanities.” Digital Humanities in Practice. Ed. Claire Warwick, Melissa Terras, and Julianne Nyhan. London: Facet Publishing, 2012. 192-216.

Wernimont, Jacqueline, and Elizabeth Losh. "Problems with White Feminism: Intersectionality and Digital Humanities.” Doing Digital Humanities. Ed. Constance Crompton, Richard Lane, and Raymond G. Siemens. London and New York: Routledge, 2016. 35-46.

Williams, George H. "Disability, Universal Design, and the Digital Humanities.” In Debates in the Digital Humanities, edited by Matthew K. Gold. Minneapolis: University of Minnesota Press, 2012. 202-12.

Willinsky, John. The Access Principle: The Case for Open Access to Research and Scholarship. Cambridge, MA: MIT Press, 2006.

i See for instance Burdick et al.; Gil and Ortega; Hockey; Losh; Liu; McPherson; Wernimont and Losh; Williams. 